\title{
Increasing Brand Attractiveness and Sales through Social Media Comments on Public Displays - Evidence from a Field Experiment in the Retail Industry
}

\author{
Erica Dubach Spiegler, Christian Hildebrand, and Florian Michahelles \\ ETH Zurich, Zurich, Switzerland \\ \{edubach, fmichahelles\} @ethz.ch \\ University of St. Gallen, St. Gallen, Switzerland \\ christian.hildebrand@unisg.ch
}

\begin{abstract}
Retailers and brands are just starting to utilize online social media to support their businesses. Simultaneously, public displays are becoming ubiquitous in public places, raising the question about how these two technologies could be used together to attract new and existing customers as well as strengthen the relationship toward a focal brand. Accordingly, in a field experiment we displayed brand- and product-related comments from the social network Facebook as pervasive advertising in small-space retail stores, known as kiosks. From interviews conducted with real customers during the experiment and the corresponding analysis of sales data we could conclude three findings. Showing social media comments resulted in (1) customers perceiving brands as more innovative and attractive, (2) a measurable, positive effect on sales on both the brand and the product in question and (3) customers wanting to see the comments of others, but not their own, creating a give-andtake paradox for using public displays to show social media comments.
\end{abstract}

Keywords: Public Displays, Digital Signage, Pervasive Advertising, Social Media, Social Networks, Field Experiment, Mixed Methods, Retail Industry.

\section{$1 \quad$ Introduction}

Public displays - sometimes referred to as digital signage and "digital out-of-home media" (DOOH) - are becoming increasingly common thanks to technological advances and rapidly declining costs [11]. Accordingly, global spending on digital displays has shown strong growth, with sales of $\$ 6.47$ billion in 2010 , which is projected to expand by $16.9 \%$ in $2011^{1}$. Not surprisingly, retailers are showing interest in business-relevant, consumer-facing applications which have the potential to change customers' interaction with retailers and their in-store experiences, giving public displays a prominent place in retail. However, despite these activities and the research interest in using public displays for advertising, it is estimated that DOOH advertising in general has not reached its full potential, largely because of the

${ }^{1}$ PQ Media http://www.pqmedia.com/about-press-20091110-dooh2009.html 
difficulty in measuring the return on investment [25]. To quantify the gap: while people on average spend $27 \%$ of their time exposed to outdoor advertising, this form of advertising in 2008 only comprised $5 \%$ of US media spending [13]. Thus, it is of a fundamental practical as well as theoretical importance to better understand underlying drivers of successful public display advertising strategies and their economic effects in terms of sales.

The field experiment described in this paper was conducted to better understand the effects of social media (SM)-based advertising on customers' attitudes and sales and as such, it was conducted in small-space retail stores (kiosks), where brandrelated SM comments were shown on public displays. The newness of this pervasive advertising application prompted an explorative approach in which interviews were used to understand customer attitudes toward using SM comments on public displays, as well as a quantitative analysis of sales data to show how these attitudes might affect sales. The collaboration with the kiosks and the quantitative analysis of the field experiment are described as a case study in "Social Networks in Pervasive Advertising and Shopping“ [7]. This paper provides further depth by adding the analysis of customer interviews and the insights gained from understanding the customer's paradoxical attitudes towards SM and public displays.

Interviews conducted during the experiment provided insight into customer opinions and the corresponding analysis of sales data showed the effect on sales, resulting in three findings: (1) SM comments resulted in customers perceiving brands as more innovative and attractive. (2) The subsequent analysis of the sales data shows that displaying SM comments in stores have a measurable, positive effect on sales on both the brand and the product in question. In addition to these findings of practical importance, the paper advances the theoretical discussion by presenting evidence that (3) customers want to see the comments of others, but not their own, creating a giveand-take paradox for using public displays to show SM comments.

\section{Related Work and Development of Hypotheses}

Pervasive Advertising [17] enables the kind of serendipity common on TV, radio and print, with the added benefit of enabling new ad types [26] such as user-generated comments. Public displays in particular allows for a broad range of content from generic advertisements to ones that are responsive [18] or interactive [9, 16]. Since advertising in general is proven to increase shareholder value through increased sales [34], pervasive advertising research is being conducted to understand how to extend traditional advertising into the domain of pervasive computing. Based on previous findings which have shown the positive influence on the brand due to increased interactivity with the brand on Facebook and customer engagement [36], we expect a positive influence of using Facebook on public displays on a brand's perceived innovativeness.

H1: The more positive a customer's attitude toward Facebook on public displays, the higher the brand's innovativeness will be perceived. 
Furthermore, SM provides retailers access to a new type of word of mouth, which is a recognized force in retail $[29,1,5]$ and has the appeal of precisely directing messages to a targeted audience. SM represents the natural technological platform for marketing based on a structured set of social relationships among admirers of a brand, i.e. a brand community [28]. Additionally, SM allows companies to listen to the opinions, wishes and complaints of their customers, as many consumers want constant connectivity, ideally in every facet of their lives [3]. Different consumer brands and retail stores are handling this opportunity and these challenges in different ways, some with spectacular success, (e.g. Nutella allowing its 6.8M Fans to send each other virtual Nutella gifts). As a result, we predict that brands will be perceived as more innovative when companies enable Facebook comments of friends on public displays.

H2: The higher customers' attitude toward seeing Facebook comments of their friends on public displays, the higher the brand's perceived innovativeness.

Research based on prototypes applied in user studies has investigated embedding brands into the natural living environment and context of people [33, 4], inferring a customer's activities for more targeted advertising [21], influencing their shopping behavior by means of persuasive strategies [27] etc. Public displays in retail stores can cater to this, thus satisfying both customer demand and taking advantage of sharing SM user comments in the sales environment to increase sales.

Past research considerably advanced our understanding of how and why consumers may engage in brand communities. However, research has also shown that privacy concerns are rising and may inhibit content production on the individual level [19], though users may nevertheless wish to consume the produced content on the social networking sites [12]. The moderating influence of the previously noted privacy concerns on the one hand and consumers tendency to enjoy seeing the content of others on the other hand, is expected to be positively related toward the brand's innovativeness. Thus, we predict:

H3a: The higher customers' attitude toward Facebook on public displays and attitude toward seeing their own Facebook comments on public displays, the higher the brand's perceived innovativeness.

H3b: The higher customers' attitude toward seeing Facebook on public displays and attitude toward seeing Facebook comments of their friends on public displays, the higher the brand's perceived innovativeness.

From the marketers' perspective, there are many strategic and operational benefits of cultivating brand communities. Brand-community participation results in a positive effect on consumers' attitude and attachment to the brand and the company [14].

From the consumers' perspective, users are interested in receiving brand announcements on their profile page, they feel they are a part of the brand communities they joined, accept friendship requests of the brand pages and value friends' opinion about a brand [23].

Past research findings explain how pervasive technologies may increase a customer's perception of a brand as being highly innovative. However, a test if this perception can also be transformed into an increase in global attractiveness and preference for the brand is still needed. Thus, we predict: 
H4a: The higher customers' attitude toward Facebook on public displays and attitude toward seeing their own Facebook comments, the lower the brand's perceived attractiveness.

H4b: The higher a customers' attitude toward seeing Facebook comments of their friends and the higher the perceived innovativeness of the brand, the higher the brand's attractiveness.

Figure 1 summarizes our research model to explain the influence of attitudes towards SM on the perception of the brand's innovativeness and the mediating role of brand innovativeness on overall brand attractiveness.

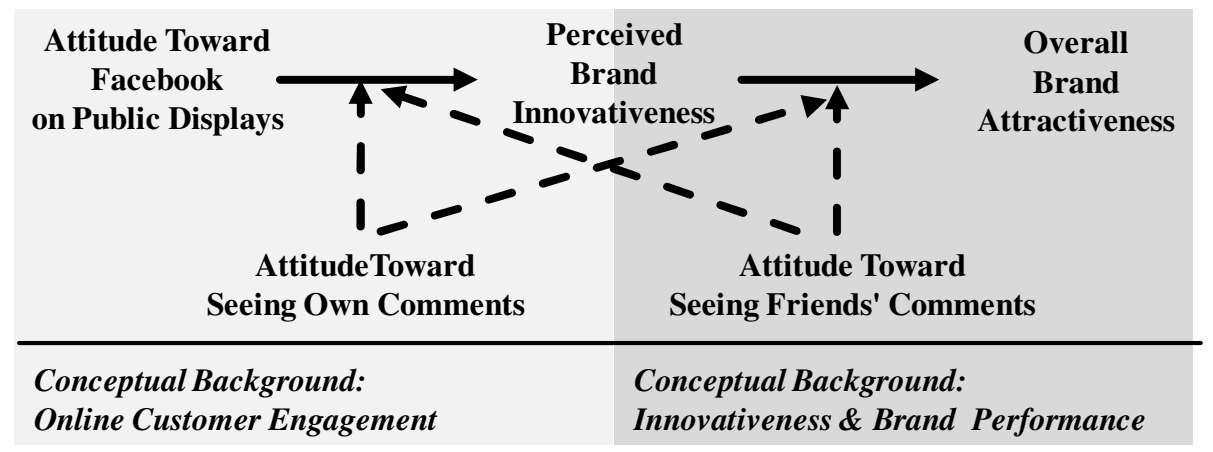

Fig. 1. Overview of Research Model

Past research considerably advanced our understanding of how using SM for brand marketing enables companies to build and maintain close relationships with consumers [20]. However, it is far less understood how consumers' attitude toward SM sites may directly influence their perception of a company active on SM in general, nor is the influence on important business variables such as sales understood. The direct link between the previously introduced developments in the area of pervasive advertising and their effect on either attitude-oriented constructs - such as the perceived innovativeness or attractiveness of a company or directly measurable effects in terms of sales - is still missing [30]. Thus, we finally test if these attitudeoriented effects transform into an increase in sales. In particular, we predict that presenting company-specific content in contrast to a control condition of unrelated content will affect sales volume of the company positively. Furthermore, based on previous work in the area of consumer behavior [32] and our previous discussion on positive influence of customer engagement on innovativeness and brand attractiveness, we expect that (1) product-specific, in contrast to brand-specific information are associated with an increase in sales, as well as (2) SM comments, in contrast to traditional advertising, are associated with an increase in sales, due to the more personal nature of SM in comparison to traditional advertising. Finally, based on previous work in pervasive advertising [17], we predict a higher sales volume for sales locations at public transport meeting places because of the higher frequency of visitors making quick purchases. 
H5: Using company-specific content on public displays leads to higher sales volume than random, company-unspecific content.

H6: Product-related content on public displays yields higher sales volume than brandrelated content.

H7: SM comments on public displays yield higher sales volume than traditional advertising.

H8: Kiosks located in public transport areas and using public displays yield higher sales volumes than kiosks in standard shopping malls or airport kiosks using public displays.

\section{Context of the Study}

We conducted a field experiment in partnership with Valora Retail, which operates around 1000 small-space stores, known as kiosks. Sales show high frequency at small volumes of convenience products such as news, sweets, tobacco and lottery: together, kiosks serve 850'000 customers per day, who buy an average of 1.7 articles. These kiosks often function as meeting points and social hubs in the areas they are located in.

In an effort to increase sales and gain third-party advertising revenues, the retailer was conducting a public display experiment involving a total of 50 kiosk locations. Of those, 16 contained suitably large, 40" screens, which we could use for displaying SM comments (see Figure 1) in the field experiment. In addition, the team gained management support to use a kiosk private label brand, the "ok.-" line of products, which allowed for greater control than would have been possible with a national or global brand. Finally, a Facebook "Brand Page" was set up for the ok.- brand in March 2010, 9 weeks ahead of the field experiment. This brand page served as the source for the SM comments shown on the public display. As long as the comments did not violate the company policy (e.g. profanity, obscenities, etc.), we collected the comments by taking the three most recent posts at $8 \mathrm{pm}$ each day, regardless of whether the sentiment towards the brand was positive or negative (see also [23]).

Experimental Setup of Field Experiment. The field experiment covered 16 kiosks all over German-speaking Switzerland, located in airports, hubs of public transport, inside shopping centers and rural areas. To experimentally test the effects of SM comments on public displays, the content shown was systematically manipulated (see below).

These 16 kiosks were all equipped with a 40" screen, which featured a standardized layout determined by the retailer: an upper bar with time and date, a lower bar with news headlines and a side bar with infotainment such as weather and horoscopes. The design was part of the retailer's public display experiments and could not be changed for our field experiment. The experimental content was shown in stores for 5 weeks from 5th of May to the 8th of June 2010, so that every one of the five experimental 
conditions was run for one week. The shown content was visible for 15 seconds within a two-minute loop. Figure 2 above shows an example of the public display placed within the kiosk environment.

Experimental Conditions. We systematically varied the content shown on the public displays. In particular, five different types of content were displayed on the public displays: in the first condition, we varied product- vs. brand-specific content. Secondly, we either presented traditional advertising vs. SM comments harvested the previous day from the ok.- Facebook fan page. Specifically, the three newest comments were collected every evening at $8 \mathrm{pm}$, including the author's first name and the initial of their last name. In addition, we had one control condition in which no manipulated content was shown. Thus, this resulted in the following conditions shown on the public display: (1) traditional advertisement of the $o k$,- brand, (2) traditional advertisement of the lead product ( $o k$,- Energy Drink), (3) SM comments from the $o k$,- Facebook Brand page, (4) SM comments from $o k$,- Facebook Brand page (ok,Energy Drink) and finally, (5) control condition (content unrelated to the $o k$,- brand).

Overall, this produced a final 2 (product vs. brand) x 2 (traditional advertising vs. social network comments) experimental design, and in addition, every kiosk was treated with a control condition where no experimental manipulations were shown. Every kiosk was randomly assigned to one of the five conditions lasting for one week each. Choosing which content to show in which location and choosing the timing was based on a completely randomized experimental design to minimize the impact of the different influences that come from the "natural" setting of this field study [16].

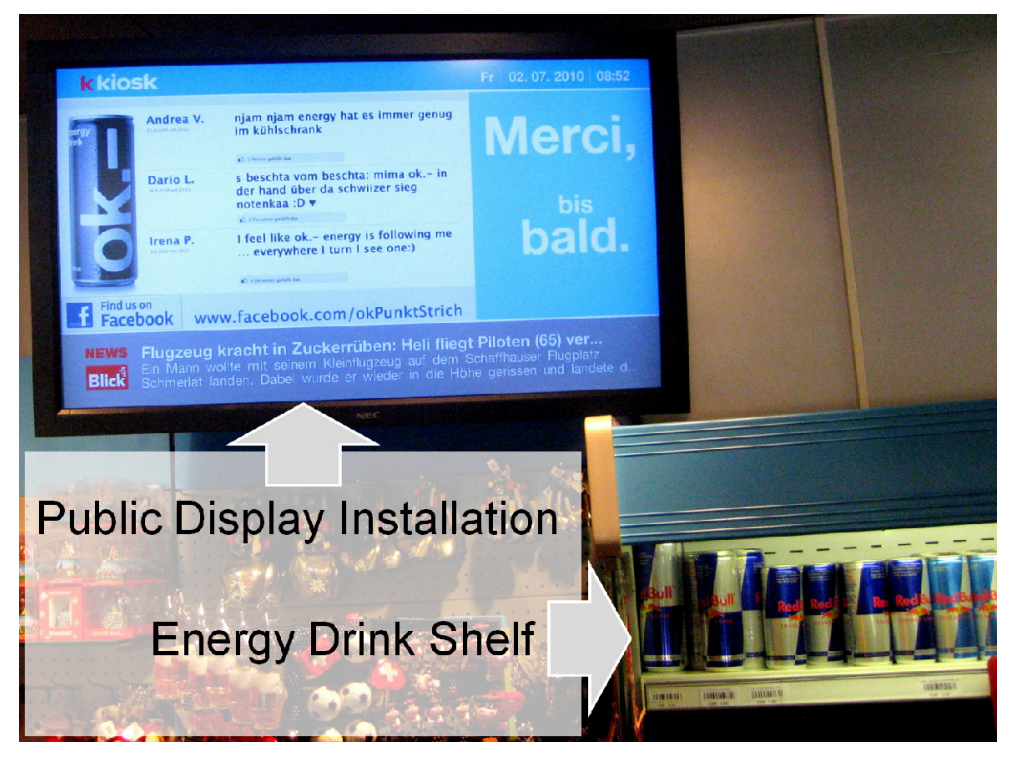

Fig. 2. Social media comments for an energy drink on public display in a kiosk 


\section{$4 \quad$ Analysis I: Customer Interviews}

During the time of the field experiment, we conducted customer interviews in parallel to measuring sales data. While the cash register sales data was central to evaluating the economic impact of public display advertising on sales, the customer interviews were conducted to better understand the general attitude toward public display advertising, as well as the attitude toward SM and Facebook and the influence on general brand attractiveness. Thus, we present the customer interviews first, and will then provide additional evidence based on quantitative sales data in the next section, Analysis II.

\subsection{Mixed Method Approach and Qualitative Interview Data}

Interviews. To explore customers' opinions regarding comments from SM on public displays, semi-structured guided interviews were conducted in kiosks showing SM comments on public displays. This method was chosen to account for the newness of the topic, hence the use of mostly open questions instead of a standardized questionnaire.

The interview questions were based on a questionnaire containing 20 questions which allowed yes / no answers with comments, except for two open questions noted below. Customers were first asked if they had noticed the display and whether they had seen the SM comments. In an open question, they were fist asked what they thought about showing SM comments on public displays in general. The next question asked if SM comments on public displays influenced their perception of the company (the comments received were coded for innovativeness of the company). Customers were also asked if this increased the attractiveness of the advertised brand, and the likelihood of purchasing products of this brand. Two questions aimed to determine whether customers would like to see their own comments displayed, and the comments of their friends, though this was hypothetical since no interviewee indicated that they recognized the people whose SM comments were being used on the public display. Since SM comments expressing both positive and negative attitudes towards the brand were shown during the field experiment, an open question asked customers for their opinion of seeing both types of comments. The final set of questions established demographic information, including Facebook usage.

A total of 131 interviews were conducted by approaching every customer in the kiosk after they had concluded a purchase. The answers were recorded on pre-printed questionnaires, which were later transcribed. The interviews were conducted at different times of the day, over the course of 10 days from 30 June to 9 July 2010, at 10 different and randomly chosen kiosk locations, in all of which SM comments were being shown on a public display.

Measurement and Coding Scheme. In a first step, the responses to the interview questions were entered and transcribed. Initial analyses revealed strong differences between participants' answers (e.g., strong rejection of SM vs. strong positive attitude toward SM comments on public displays). To capture these different nuances in customers' answers, for example comments about privacy, a five point Likert scale was set up to capture differences between comments and to analyze the general 
tendencies and relationships between variables. A five point Likert scale was used to measure (1) customers' general attitude toward displaying SM comments on public displays, (2) their attitude toward imagining seeing their own comments, (3) their attitude toward imagining seeing comments of others and (4) the perceived innovativeness of the brand and the brand's attractiveness. The scale was set up so that two independent coders assigned values between -2 for a strong negative attitude to +2 for a strong positive attitude with a neutral point at zero. To test the reliability of the scales, we conducted interrater reliability tests which are based on the degree of agreement among the two independent raters [31], supporting the quality and substantial degree of consensus with all values above .70 ( $\mathrm{M}_{\text {Cohen's Kappa }}=.814$, $\left.\mathrm{M}_{\text {Intraclass Correlation }}=.875(\mathrm{Min}=.70, \mathrm{Max}=.95)\right)$. Consumers' use of Facebook was measured by the number of Facebook use per day and consumers use of Facebook on mobile devices was measured by a binary variable (use vs. no use). Consumers' age was measured by discrete variable with six categories (see results section below in further detail). The SM comments themselves were not further analyzed for content, sentiment or attitude, though the interviews did capture customers' opinion of seeing both negative and positive comments.

\subsection{Interview Results}

Consumer Perceptions of Brand Innovativeness. In this first analysis, we were particularly interested in two questions: (1) consumers' perception of the brands innovativeness, as dependent on their attitude toward displaying Facebook comments on public displays in a retail store, and (2) their attitude toward imagining seeing their own comments, especially in comparison to their attitude toward imagining seeing the comments of others (e.g., friends and acquaintances) on public displays. In addition, four control variables were analyzed: consumers' age, being a fan of the $o k$,- brand's Facebook brand site, intensity of Facebook use per day and use of Facebook Mobile. Table 1 summarizes our results based on a multivariate linear regression model.

Table 1. Results of Multivariate Linear Regression: Drivers to Explain Brand's Perceived Innovativeness

\begin{tabular}{lrrrr}
\hline & Estimate & \multicolumn{2}{c}{ SE } & \multicolumn{1}{c}{ t-Value $\mathrm{p}$-Value } \\
\hline Constant & .033 & .134 & .243 & .808 \\
Attitude Toward Facebook on PD (FBPD) & .174 & .088 & $1.988^{*}$ & .049 \\
Attitude Seeing Friends' Comments (FC) & .109 & .052 & $2.116^{*}$ & .037 \\
Attitude Seeing Own Comments (OC) & .039 & .047 & .832 & .407 \\
FBPD $\times$ FC & -.113 & .084 & -1.349 & .180 \\
FBPD $\times$ OC & .717 & .199 & $3.6^{* * *}$ & $<.001$ \\
Facebook Mobile Use (MOB) & -.343 & .158 & $-2.165^{*}$ & .032 \\
Facebook Use (in Hours / Day) (FB) & -.023 & .022 & -1.043 & .299 \\
MOB $\times$ FB & .063 & .030 & $2.086^{*}$ & .039 \\
Age & .009 & .030 & .291 & .771 \\
Fan of Facebook Brand Site & .111 & .242 & .459 & .647 \\
\hline F-Value & $4.455^{* * *}$ & & & \\
$\mathrm{R}^{2}$ & .28 & & & \\
\hline$* * * \mathrm{p}<.001, * * \mathrm{p}<.01, * \mathrm{p}<.05$ & \multicolumn{5}{l}{}
\end{tabular}


As expected, we found a positive and significant influence of consumers' attitude toward displaying Facebook comments on public display (FBPD) in a retail store as well as consumers intention to see the comments of their friends (FC) on the perceived innovativeness of the company $\left(\right.$ Beta $_{\mathrm{FBPD}}=.17, \mathrm{t}(119)=1.988, \mathrm{p}<.05$; Beta $\left._{\mathrm{FC}}=.11, \mathrm{t}(119)=2.116, \mathrm{p}<.05\right)$, supporting hypotheses 1 and 2 .

While consumers' attitude toward seeing own comments (OC) had no significant influence on perceived innovativeness alone $\left(\right.$ Beta $\left._{\mathrm{OC}}=.04, \mathrm{t}(119)=.832, \mathrm{p}>.40\right)$, we found the predicted interaction between consumers' intention to see their own comments and the general attitude toward integrating Facebook on public displays $\left(\right.$ Beta $\left._{\mathrm{FBPD} \times \mathrm{OC}}=.72, \mathrm{t}(119)=3.600, \mathrm{p}<.001\right)$, in support of hypothesis $3 \mathrm{a}$ and failing to support hypothesis $3 \mathrm{~b}$. Figure 3 illustrates the steeper regression slope compared to the simple main effect without controlling for consumers' intention to see one's own comments. Thus, we may already hypothesize that consumers' intention to see their own comments in contrast to seeing others may have different effects on subsequent evaluations of retail stores. This is analyzed in detail in the next section.

Finally, our analyses also revealed a significant interaction between consumers' use of Facebook Mobile (MOB) and intensity of Facebook use (FB) in a positive direction $\left(\right.$ Beta $\left._{\mathrm{MOB} \times \mathrm{FB}}=.06, \mathrm{t}(119)=2.086, \mathrm{p}<.05\right)$. This result reveals that intense Facebook or Mobile applications use alone does not drive consumers' perception of a company's innovativeness, but rather the interaction of the two variables. Since the main effect of mobile use is significant but negative, this is an example of a disordinal interaction, i.e. mobile use needs to be interpreted in combination with the interaction of Facebook usage [2].

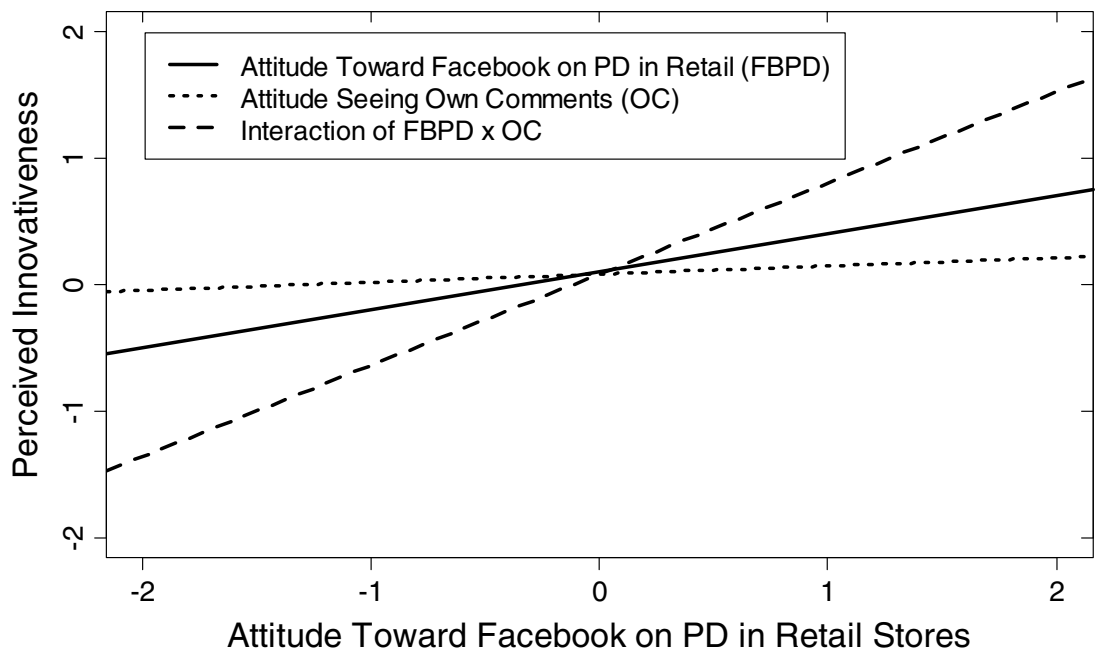

Fig. 3. Illustration of interaction between attitude toward Facebook and attitude to see own comments on public displays on the company's perceived innovativeness

Overall, these initial results have shown that consumers build a strong link between a company's activity on Facebook brand sites and their intention to see their own comments on public displays on the perceived innovativeness of the brand. 
Interestingly, the influence of consumers' intention to see the comments of other users was not dependent on this interaction and may have more general implications than the dependencies to see one's own comments. However, (1) it is not clear how innovativeness is further related to the overall attractiveness of the focal brand and (2) how the tension between varying attitudes in seeing one's own compared to friends' comments is moderating this relationship. This detailed analysis will be part of the next section.

Influence on Overall Brand Attractiveness. As we have shown above, a consumer's attitude toward the integration of Facebook in a retail store is positively related to the perceived innovativeness of the company. Now we will expand our analyses by assessing the mediating role of innovativeness on brand attractiveness and the moderating role of consumers' attitude toward seeing own comments, as well as seeing friends' comments on public displays. To test our previous hypotheses, we conducted a moderated mediation analysis [24]. Thus, we use a mediation model which simultaneously estimates the influence of the two moderators (seeing own comments and seeing friends' comments). This model has the advantage over testing every specified hypothesis independently (e.g. with linear models or ANOVAs) by reducing the risk of an otherwise increasing type II error of statistical testing.

Since the effects in the mediator model remain equal compared to our previous analyses (interaction of attitude toward Facebook and attitude toward seeing own comments on perceived innovativeness of the brand $\left(\right.$ Beta $_{\mathrm{FBPD} \times O C}=.58, \mathrm{t}(125)=3.616$, $\mathrm{p}<.001)$ ), it will now be important to evaluate how a brand's attractiveness is affected.

Our analysis revealed a strong main effect of consumers' attitude toward integrating Facebook on public displays on overall attractiveness of the brand $\left(\right.$ Beta $\left._{\mathrm{FBPD}}=.60, \mathrm{t}(123)=9.612, \mathrm{p}<.001\right)$, as well as a marginal positive effect of watching the comments of others $\left(\operatorname{Beta}_{\mathrm{FC}}=.07, \mathrm{t}(123)=1.891, \mathrm{p}=.06\right)$. While the latter influence of watching others significantly interacts with perceived innovativeness of the brand to increase the attractiveness of a focal brand $\left(\right.$ Beta $_{\mathrm{INNO} \times \mathrm{FC}}=.17$, $t(123)=2.062, p<.05)$, the influence of consumers' attitude toward seeing their own comments is as predicted, i.e. we find empirical support that although the possibility to see one's own comments was positively related to the brand's innovativeness (see results of the previous section), the main effect, as well as the interaction with the attitude toward integrating Facebook, is significantly negatively related to the attractiveness of a brand $\left(\right.$ Beta $\left._{\mathrm{FBPD} \times \mathrm{OC}}=-.25, \mathrm{t}(123)=1.988, \mathrm{p}<.05\right)$.

Thus, we find support for $\mathrm{H} 4$ ( $\mathrm{a}$ and $\mathrm{b}$ ) and our prediction that disclosing personal information in a public domain, such as public displays in a retail store, may have negative consequences regarding the overall attractiveness of a brand. In contrast, expecting to see others is strongly positively related to the attractiveness of the brand.

This contradiction is of major importance, since the inherent value of integrating SM into public displays is strongly dependent on the content of its users - however, if privacy concerns hold individuals back from adding content, while expecting others to do so, the irony and paradox of handling both competing preferences at the individual level may inhibit harnessing the full potential of pervasive advertising with public displays. 
(A)

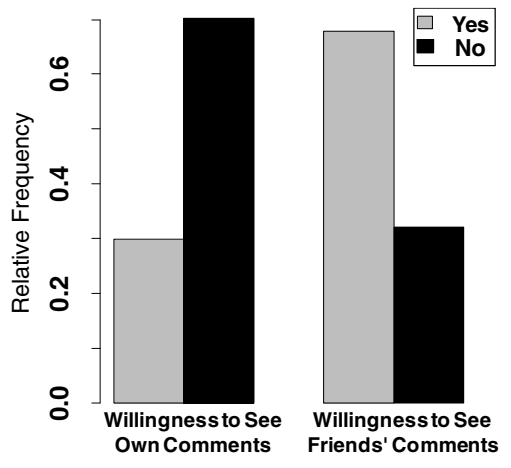

(B)

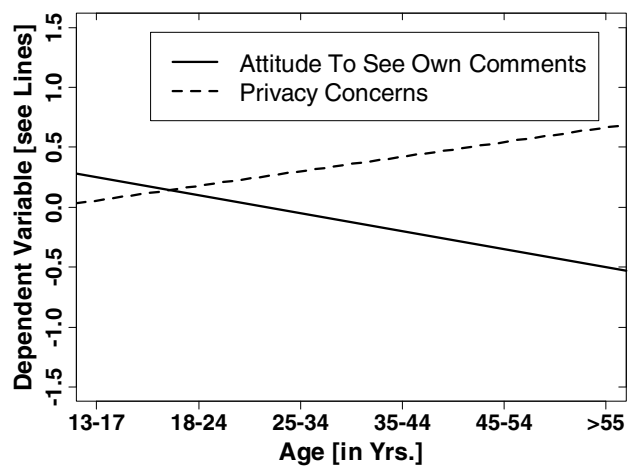

Fig. 4. (A) proportion of consumers' willing to see their own vs. seeing comments of other users; (B) influence of consumers' age on privacy concerns and attitude to see own comments

To further explore this pattern of results, we analyzed the proportion of attitudes toward seeing one's own comments compared to seeing the comments of others by aggregating the data into either general positive or general negative attitude (see Figure 3) and found that both categories are highly statistically different $\left(\chi^{2}(1, \mathrm{~N}=131)=18.493, \mathrm{p}<.001\right)$. Moreover, additional analyses revealed that a strong demographic influence underlies this effect: the older consumers are, the less likely they are to want to see their own comments $\left(\right.$ Beta $\left._{\mathrm{Age}}=-.15, \mathrm{t}(129)=3.909, \mathrm{p}<.001\right)$ and the higher is their perception of privacy issues $\left(\right.$ Beta $\left._{\mathrm{Age}}=.12, \mathrm{t}(129)=2.466, \mathrm{p}<.05\right)$.

Overall, we find that this inherent contradiction of handling consumer preferences to watch the SM content of others, while promoting content production at the individual level, may be one of the key challenges in the early phase of adoption and market diffusion of business models for SM on public displays.

Since the interviews clearly demonstrate that seeing others' SM comments on public displays has a positive effect on customers' overall perception of the attractiveness of the brand, the next question is to determine whether this translates to an increase in sales. For this, we analyzed the sales data gathered during the field experiment, as described above.

\section{$5 \quad$ Analysis II: Sales Data}

In the course of the field experiment, sales data was gathered for one of the company's new private label products: a type of energy drink. The data was analyzed to test hypotheses 5 to 8 and to determine the effects on sales of displaying SM comments of the company's new energy drink on public displays. This section details the field experiment conducted and results obtained. Complementary to the previous interview results regarding the more general customer attitudes toward the brand in relation to SM comments on public displays, this section will reveal particular evidence of how customers' buying behavior is influenced by these SM comments on public displays. 


\subsection{Methodology}

Measurement. Sales data from each kiosk participating in the field experiment was transmitted to the retailers' central business intelligence system every night. From there, the retailer provided sales data for all the private label products. This allowed testing the effects of the experiment, which targeted the private label brand as a whole, and also the top-seller energy drink in particular. The data also covered the 5 months leading up to the experiment and provided insight into the development of sales prior to the field experiment. This historical data showed an emerging (rising) trend over time and was used to adjust the experiment data to eliminate this trend and only measure the experimental effect based on the conducted manipulations during the experimental phase.

Statistical Model. In order to test our previous hypotheses and experimental conditions on sales, we applied a repeated measures linear mixed model (LMM) [22]. LMM's provide us with additional flexibility in model specification and allows us to account for inherent store-to-store variation and store heterogeneity within our field experiment as well as to model repeated effects on single stores over time. The respective error terms are assumed to be independent between different stores. Since all stores can be assumed to be randomly selected from a larger population, we specified the respective store as a random effect within our model, since we are not interested in specific effects of single stores but rather the hypothesized effects of our experimental manipulations. Additionally, since we have repeated measurements of single stores over time with high likelihood of correlation with each other (sales volume in one week is not independent of sales volume in the following week), we fitted several LMM's with varying covariance structure as a general procedure for model selection [15]. The general idea is to find the most parsimonious model specification that fits the correlated time series of sales data well. Therefore we started with a simple first-order autoregressive covariance structure (i.e., constant covariance between two measures and increasing the exponent of the covariance parameter with increased time steps) and expanded the model complexity systematically by applying an autoregressive moving-average, a toeplitz-based covariance matrix as well as a more complex unstructured covariance matrix [see 15 for detailed information on how these covariance matrices are specified]. As a general procedure to choose the optimal model specification, we conducted likelihood-ratio (LR) tests between all nested model's [8]. Overall, the best fitting model was based on the unstructured covariance matrix and outweighs its higher number of to be estimated parameters (e.g., testing unconstrained (UN) vs. autoregressive (AR) model with a chi-square distributed LR test of $-2 \mathrm{LL}_{\mathrm{UN}}=842.25$ vs. $\left.-2 \mathrm{LL}_{\mathrm{AR}}=890.66, \chi^{2}(1,13)=48.41, \mathrm{p}<.001\right)$.

\subsection{Experimental Results}

To enable showing SM comments, companies must conduct substantial investments in public displays, as well as investments in organization and infrastructure. Thus, it is important to test for measurable effects in terms of sales volume and to quantify them. Table 2 summarizes the results of the LMM. 
As predicted and in support of H5, showing particular and domain related content is positively related to higher sales volume than unspecific random content: the experimental variation of the panel content yielded a significant positive main effect on sales in contrast to the control condition where only random and unspecific content was displayed $(\mathrm{F}(1,91)=4.12, \mathrm{p}<.05)$.

Furthermore, presenting specific product information in contrast to brand specific content yielded the expected main effect $(\mathrm{F}(1,601)=9.628, \mathrm{p}<.01)$, suggesting that product related content reveals stronger and more behavioral stimulating and compulsive effects than brand presentations, supporting H6.

Table 2. Parameter estimates of fixed effects from repeated measures LMM

\begin{tabular}{lllll}
\hline & Estimate & SE & t-Value & p-Value \\
\hline Experimental Condition $^{1}$ & 24.5 & 12.06 & 2.03 & .045 \\
Brand Presentation $^{2}$ & -33.88 & 10.89 & -3.11 & .002 \\
Traditional Advertising $^{3}$ & 30.69 & 10.51 & 2.92 & .004 \\
Brand $\times$ Traditional Advertising $^{2}$ & 9.74 & 15.42 & 0.63 & .528 \\
Small Kiosk Type $^{4}$ & -40.43 & 8.63 & -4.68 & $<.001$ \\
Sales Location $^{5}=$ Public Transport $^{5}$ & 26.62 & 8.21 & 3.24 & $<.001$ \\
Sales Location $^{5}=$ Local Retail & 21.04 & 15.95 & 1.32 & .187 \\
Sales Location $^{5}=$ Shopping Mall & -1.57 & 17 & -0.09 & .926 \\
Urban Area $^{6}$ & 0.88 & 14.58 & 0.06 & .952 \\
\hline \hline
\end{tabular}

${ }^{1)}$ Reference Category = Control Condition

4) Reference Category = Large Kiosk Type

${ }^{2)}$ Reference Category = Product Presentation

${ }^{3)}$ Reference Category = Facebook Messages

${ }^{5)}$ Reference Category = Airport Location

${ }^{6)}$ Reference Category = Non-Urban Area

Contrary to what we expected, we found a strong main effect of traditional advertising in contrast to SM comments $(\mathrm{F}(1,357)=28.641, \mathrm{p}<.01)$, thus failing to support H7. Building on previous work on information processing [32], this finding has to be reflected with regard to the general nature of a kiosk: consumers tend to selectively process given information at the point-of-sale due to consumers' time constraints. This means that retailers have to choose public display strategies that allow for very fast information processing with low cognitive involvement. Actively reading SM comments requires cognitive capacity as well as motivation to process textual stimuli, whereas easy to process visual cues of classical advertising are not dependent on this assumption and probably leading to this advantage of traditional advertising at the point of sale. Analyzing the control variables showed a significant effect for the respective sales area $(\mathrm{F}(3,1411)=5.267, \mathrm{p}<.01)$, and follow up contrasts revealed that this effect was attributed to the difference between airport and public transport locations $\left(\mathrm{M}_{\text {Airport - PublicTransport }}=-26.62, \quad \mathrm{SE}=8.21, \mathrm{p}<.01\right), \quad$ supporting hypothesis 8 . This suggests that retailers should strongly account for location specific effects that are dependent on the general target audience: while airport area stores are probably more frequented by international consumers that aren't familiar with a 
specific national brand, and possibly the language of the SM comments, this effect is reversed for locations with a high local awareness, like local public transport areas or shopping centers.

However, there was no significant effect for the degree of urbanity $(F(1,774)=.004$, n.s.) which underlines that the general effect of SM comments on public displays is not dependent on highly urban in contrast to non-urban areas. Note that although airport locations are usually in more urban areas, the general effect between urban and less urban places is less crucial - thus, retailers promoting national brands should focus more on installations on the right target location regarding the sales place, rather than distinguishing between urban and less urban places.

\section{Discussion}

Overall, the interviews conducted showed that customers attitude towards SM comments on public displays affect the perceived innovativeness of the brand, which in turn increases the overall brand attractiveness. Within these effects though lies the paradox of customers wanting to see comments written by friends on the one hand, while not wanting to see their own comments on the other. Regardless of this, displaying SM comments on public displays is positively associated with sales.

Perception of Brand Innovativeness and Attractiveness. The interviews showed that customers perceive the brand to be innovative due to the SM comments shown on public displays. The perceived innovativeness held true in general for customers who liked seeing SM comments of other people.

In addition to the perception of innovativeness of the brand, customers responded that the SM comments on public displays increased the attractiveness of the brand being shown.

Effect on Sales. The sales data analyzed clearly showed an increase in sales for both product-related SM comments as well as brand-related SM comments, though the product-related SM comments performed slightly better than general brand-related SM comments. However, for both, traditional advertising had a stronger effect still, probably due to the more cognitive as well as time consuming processing of the textbased SM messages in contrast to visual stimuli of classical advertising.

Furthermore, the analysis of our control variables revealed that the prevailing store circumstances are highly relevant for deriving effective retail strategies: while significant sales effects can be revealed by SM comments on public displays in local transportation areas, this effect is reversed for locations that are frequented by more international consumers.

Give-and-Take Paradox. Both qualitative and quantitative analyses point to the positive effects of using SM comments on public displays. However, while expecting to see SM comments of other customers is strongly positively related to the attractiveness of the focal brand, the data also provides support that customers feel that disclosing their own personal information on public displays in a retail store may 
have negative consequences on the overall attractiveness of a brand. Additionally, customers expressed concerns over privacy which need to be taken into account.

For the retailer, this paradox poses a problem in implementing a pervasive advertising strategy that relies on SM comments provided by customers. Since the medium is of major importance to advertisers, several advertisers have taken the intermediary step of repositioning their content to make it look similar to SM comments from customers in an effort to gain greater consumer acceptance [10]. However, this harbors the risk that the brand might be perceived as insincere, which violates WOM principles. Also, having the company generating content might be a time-consuming effort, since research suggests that due to the customized nature of using content from SM, the timeliness of the content is crucial in order to be meaningful, since delays might invalidate the context [6].

Implications. Our results significantly enrich our understanding of the efficiency as well as the effectiveness of pervasive advertising strategies that rely on SM comments on public displays. Our interviews and field experiment revealed new insights regarding the effectiveness of pervasive computing applications on public displays. Both data from the interviews, as well as the analysis of sales data showed that the integration of social SM on public displays results in measureable effects in terms of brand awareness, willingness to purchase and ultimately on sales.

For the sales data, this was true especially for product-specific SM comments and less so for general brand-related comments. As traditional advertising content still trumped SM comments in this context of busy small-space shops selling lowinvolvement products, we conclude that the use of SM comments needs to be carefully evaluated. The context of customers ability to process textual stimuli in a shopping environment needs to be considered, possibly resulting in mixing traditional advertising with SM content.

Importantly, customers' paradox attitudes towards wanting to see the comments of others, but without showing their own needs to be taken into account, especially in view of the documented privacy concerns.

Limitations. Though we applied a very careful, fully randomized and balanced experimental design and to have controlled for external variability, ongoing local promotions, as well as external events, might have had relevant, spurious and hard to quantify effects for our respective kiosks. Ideally, the loop of our experimental variations should have been longer to be extensively processed by customers. In addition, we had a sample of 16 kiosks - highly unequal in terms of location, sales volume and so forth. Although our statistical model is ideal and state-of-the-art to account for such variability, future work could attempt to gain access to a larger sample size.

Most importantly the experimental setup of the public display at the point-of-sale and the basic screen layout were constrained by the retailer. Since we were working within an existing experiment of our industry partner, the recommended factors for placement of the public display, the content mix or format [16], could not be implemented. Any future experiment would need to attempt to control these factors. 


\section{Conclusions}

Three main findings are presented that support the use of SM comments in pervasive advertising: (1) Showing SM comments on public displays increases customers' perception of the innovativeness and the attractiveness of the brand. (2) The effect on sales is positive - especially for SM comments relating to a specific product over a brand - though traditional advertising still has a stronger effect. Finally, (3) a giveand-take paradox exists in which customers' are influenced by whether they see SM comments from other people, which affects their opinions positively, versus a conflicted opinions when their own comments are shown. This, together with privacy concerns, poses a challenge for retailers.

Pervasive advertising researchers should consider developing systems that not only embrace customers fluent in the use of SM users but also to those who are not, in order to increase the positive perception of retail brands. Clearly, pervasive advertising research should focus more on local contexts and target groups, in order to more effectively exploit context-related SM content. The give-and-take paradox identified in this field experiment poses the challenge of designing a system that protects identities while still allowing friends to recognize each other on the screen.

Showing comments from SM on public displays improves the perception of innovativeness and the attractiveness of a brand, and - especially if they are productrelated vs. brand-related - enhances sales. However, classical advertising still has general advantages due to a lower cognitive load regarding the route of information processing. This leads to our recommendation that a mix of the two advertising strategies should be based on careful analysis of the shopping environment and target group.

Future studies should assess how consumers' privacy concerns can be addressed effectively and examine additional forces that may also moderate the stated give-andtake paradox (e.g., different consumer segments with a stronger tendency to disclose personal information and explicitly gaining value by posting their own comments). Furthermore, an extension on other product categories can help to better understand possible differences between high- vs. low-involvement products. Network based metrics could be applied to expand pervasive technologies toward identifying social hubs in the intersection of real- and online social networks. Finally, the effect on consumers' buying behavior due to semantic differences (e.g. negative vs. positive comments, specific vs. abstract, etc.) in SM comments could be analyzed.

\section{References}

1. Agarwal, R., Gupta, A.K., Kraut, R.: The Interplay between digital and social networks. Information Systems Research 19(3), 243-252 (2008)

2. Aiken, L.S., West, S.G.: Multiple regression: Testing and interpreting interactions. Sage, Newbury Park (1991)

3. Arel, S.: The Emergence of Social Media in Digital Signage (accessed July 2011), http: / /www. ucview.com/pdf/ UCView_Social-Media-in-Digital-Signage.pdf 
4. Bauer, C., Spiekermann, S.: Conceptualizing Context for Pervasive Advertising. In: Müller, J., Alt, F., Michelis, D. (eds.) Pervasive Advertising. Springer (2011)

5. Chevalier, J.A., Mayzlin, D.: The Effect of Word of Mouth on Sales: Online Book Reviews. Journal of Marketing Research (2006)

6. Di Ferdinando, A., Rosi, A., Lent, R., Manzalini, A., Zambonelli, F.: MyAds: A system for adaptive pervasive advertisements. Pervasive and Mobile Computing 5 (2009)

7. Dubach Spiegler, E., Michahelles, F., Hildebrand, C.: Social Networks in Pervasive Advertising and Shopping. In: Müller, J., Alt, F., Michelis, D. (eds.) Pervasive Advertising. Springer (2011)

8. Fitzmaurice, G.M., Laird, N.M., Ware, J.H.: Applied Longitudinal Analysis. Hoboken (2004)

9. Hardy, R., Rukzio, E., Holleis, P., Wagner, M.: Mobile Interaction with Static and Dynamic NFC-based Displays. In: Mobile HCI (2010)

10. Jarrett, K.: Interactivity is Evil! A critical investigation of Web 2.0. First Monday 13 (2008)

11. Kuikkaniemi, K., Giulio, J., Turpeinen, M., Hoggan, E., Müller, J.: From Space to Stage: How Interactive Screens Will Change Urban life. IEEE Computer 44(6), 40-47 (2011)

12. Lampe, C., Ellison, N., Steinfeld, E.: Changes in use and perception of facebook. In: ACM Conference on Computer Supported Cooperative Work (2008)

13. Li, K., Edgecliffe-Johnson, A.: Clear Channel Outdoor Fights Back. Financial Times (2010)

14. McAlexander, J., Schouten, J., Koenig, H.: Building Brand Community. Journal of Marketing 66, 38-54 (2002)

15. McCulloch, C.E., Searle, S.R.: Generalized, Linear, and Mixed Models. John Wiley and Sons (2000)

16. Michelis, D., Send, H.: Engaging Passers-by with Interactive Screens. In: 2nd Workshop on Pervasive Advertising, Lübeck, Germany (2009)

17. Müller, J., Alt, F., Michelis, D.(eds.): Pervasive Advertising. Springer Human-Computer Interaction (September 2011)

18. Müller, J., Exeler, J., Buzeck, M., Krüger, A.: ReflectiveSigns: Digital Signs That Adapt to Audience Attention. In: Tokuda, H., Beigl, M., Friday, A., Brush, A.J.B., Tobe, Y. (eds.) Pervasive 2009. LNCS, vol. 5538, pp. 17-24. Springer, Heidelberg (2009)

19. Nosko, A., Wood, E., Molema, S.: All about me: Disclosure in online social networking profiles: The case of FACEBOOK. Computers in Human Behavior 26(3) (2010)

20. Palmer, A., Koenig-Lewis, N.: An experiential, social network-based approach to direct marketing. Direct Marketing: An International Journal 3(3), 162-176 (2009)

21. Partridge, K., Begole, B.: Activity-based Advertising. In: Müller, J., Alt, F., Michelis, D. (eds.) Pervasive Advertising. Springer (2011)

22. Pinheiro, J., Bates, D.: Mixed-Effects Models in S and S-PLUS. Springer, New York (2000)

23. Pletikosa, I., Michahelles, F.: Understanding Social Media Marketing: A Case Study on Topics, Categories and Sentiment on a Facebook Brand Page. In: 15th MindTrek Conference, Helsinki (2011)

24. Preacher, K.J., Rucker, D.D., Hayes, A.F.: Addressing Moderated Mediation Hypotheses: Theory, Methods, and Prescriptions. Multivariate Behavioral Research 42(1), 185-227 (2007)

25. Quercia, D., Di Lorenzo, G., Calabrese, F., Ratti, C.: Mobile Phones and Outdoor advertising: Measurable advertising. IEEE Pervasive Computing (2011) 
26. Ranganathan, A., Campbell, R.: Advertising in a pervasive computing environment. In: 2nd International Workshop on Mobile Commerce, Atlanta, USA, September 28 (2002)

27. Reitberger, W., Meschtscherjakov, A., Mirlacher, T., Tscheligi, M.: Ambient Persuasion in the Shopping Context. In: Müller, J., Alt, F., Michelis, D. (eds.) Pervasive Advertising. Springer (2011)

28. Schau, H., Muñiz, A., Arnould, E.: How Brand Community Practices Create Value. Journal of Marketing 73, 30-51 (2009)

29. Shankar, V., Venkatesh, A., Hofacker, C., Naik, P.: Mobile Marketing in the Retailing Environment: Current Insights and Future Research Avenues. Journal of Interactive Marketing 24(2) (2010)

30. Strohbach, M., Martin, M.: Toward a Platform for Pervasive Display Applications in Retail Environments. IEEE Pervasive Computing 10(2), 19-27 (2011)

31. Tinsley, H., Weiss, D.J.: Interrater reliability and agreement. In: Tinsley, H.E.A., Brown, S.D. (eds.) Handbook of Applied Multivariate Statistics and Mathematical Modeling, pp. 95-124. Academic Press, San Diego (2000)

32. Trusov, M., Bucklin, R.E., Koen, P.: Effects of Word-of-Mouth Versus Traditional Marketing. Journal of Marketing 73(5), 90 (2009)

33. van Waart, P., Mulder, I., de BontMüller, C.: Meaningful Advertising. In: Müller, J., Alt, F., Michelis, D. (eds.) Pervasive Advertising. Springer (2011)

34. Vakratsas, D., Ambler, T.: How Advertising Works: What Do We Really Know? Journal of Marketing 63 (1999)

35. Vargo, S., Lusch, F.: Evolving to a New Dominant Logic for Marketing. Journal of Marketing 68 (2004)

36. Verhoef, P., Reinartz, W., Krafft, M.: Customer Engagement as a New Perspective in Customer Management. Journal of Service Research 13(3), 247-252 (2010)

37. Zhu, F., Zhang, X.: Impact of Online Consumer Reviews on Sales: The Moderating Role of Product and Consumer Characteristics. Journal of Marketing 74 (2010) 